NOTA CIENTÍFICA

\title{
ENRAIZAMENTO ADVENTÍCIO DE ESTACAS SEMILENHOSAS DE CULTIVARES DE PESSEGUEIRO
}

\section{ADVENTITIUS ROOTING OF PEACH CULTIVARS SEMIHARDWOOD CUTTINGS}

\author{
Ubirajara Ribeiro MINDÊLLO NETO' \\ Charles Allan TELLES ${ }^{2}$ \\ Luiz Antonio BIASI ${ }^{3}$
}

\begin{abstract}
RESUMO
O presente trabalho foi realizado com o objetivo de avaliar o potencial de enraizamento de estacas semilenhosas de pessegueiros das cultivares Capdeboscq, Charme, Chimarrita, Della Nona, Eldorado, Eragil, Granada, Jubileu, Leonense, Maciel, Marfim, Ouro, Pampeano, Precocinho e Riograndense tratadas com ácido indolbutírico (AIB) na concentração de 1000 $\mathrm{mg} \mathrm{dm}^{-3}$, com imersão rápida de $5 \mathrm{~s}$. O experimento foi realizado na Embrapa - SNT Canoinhas (SC). As estacas foram coletadas em março e preparadas com $15 \mathrm{~cm}$ de comprimento e diâmetro entre 4 e $6 \mathrm{~mm}$, deixando-se um par de folhas cortadas ao meio na sua parte superior. $O$ plantio das estacas foi feito em casa-de-vegetação com nebulização intermitente, em canteiros de $3 \mathrm{~m}^{2}$, contendo como substrato areia textura média, permanecendo durante 81 dias nesse ambiente. $O$ delineamento experimental foi o inteiramente casualizado com seis repetições e 12 estacas por parcela. As maiores porcentagens de enraizamento foram obtidas com as cultivares Marfin $(90,27 \%)$, Eldorado $(79,16 \%)$, Maciel $(76,38 \%)$ e Leonense $(69,44 \%)$. Já as cultivares Granada, Ouro, Pampeano e Riogandense apresentaram baixo potencial de enraizamento e desenvolvimento das raízes.
\end{abstract}

Palavras-chave: Prunus persica; estaquia; propagação vegetativa; ácido indolbutírico.

\begin{abstract}
The aim of this work was to evaluate the rooting potential of semihardwood cuttings from peach cultivars Capdeboscq, Charme, Chimarrita, Della Nona, Eldorado, Eragil, Granada, Jubileu, Leonense, Maciel, Marfim, Ouro, Pampeano, Precocinho and Riograndense treated with indolbutiric acid (IBA) in concentration of $1000 \mathrm{mg} \mathrm{dm}^{-3}$, with fast immersion for $5 \mathrm{~s}$. The experiment was realized in the Embrapa -SNT Canoinhas (SC). The cuttings had been collected on march, prepared with 15 $\mathrm{cm}$ of length, diameter among 4 to $6 \mathrm{~mm}$, while leaving one pair of leaves cut to the way in its top side. The plantation of the cuttings has been made at greenhouse with intermittent mist in seedbeds of $3 \mathrm{~m}^{2}$, containing as substrate sands average texture remaining during 81 days in that environment. The experiment was laid out as full randomized with six replicates and 12 cuttings per experimental plot. The bigger percentages of rooting cutting were obtained with the cultivars Marfin (90.27\%), Eldorado (79.16\%), Maciel (76.38\%) and Leonense (69.44\%). The cultivars Granada, Ouro, Pampeano and Riograndense presented low rooting potential and root development.
\end{abstract}

Key-words: Prunus persica; cutting; vegetative propagation; indolbutiric acid.

\footnotetext{
${ }^{1}$ Engenheiro Agrônomo, Mestre em Agronomia, Petróleo Brasileiro S/A. Rua Rio Quixito, 01. Vila Buriti. CEP 69075-831. Manaus - AM, Brasil. E-mail: ubirajaraneto@petrobras.com.br

${ }^{2}$ Engenheiro Agrônomo, Mestre em Agronomia, Cooperativa Castrolanda. Praça dos Imigrantes, 3. Colônia Castrolanda. CEP 84165-970. Castro - PR, Brasil. E-mail: charles.allan@bol.com.br.

${ }^{3}$ Engenheiro Agrônomo, Doutor em Agronomia, Professor do Departamento de Fitotecnia e Fitossanitarismo. Setor de Ciências Agrárias, Universidade Federal do Paraná - UFPR. Caixa Postal 19.061. CEP 81531-990. Curitiba-PR, Brasil. Bolsista de Produtividade em Pesquisa do CNPq. E-mail: biasi@ufpr.br. Autor para correspondência.
} 


\section{INTRODUÇÃO}

A propagação por estaquia, na produção de mudas de pessegueiro, pode ser mais vantajosa que a tradicional enxertia pela facilidade de execução e redução do tempo necessário à produção da muda, além de evitar alguns inconvenientes da enxertia, como a incompatibilidade. Pode ainda ser empregada na produção de cultivares copa e de porta-enxertos.

No Brasil, a propagação do pessegueiro está baseada na enxertia sobre porta-enxertos provenientes de sementes, retirados de frutos destinados para indústria (FACHINELLO et al., 1982; CHALFUN et al., 1994; TONIETTO et al., 1997; FINARDI, 1998; HARTMANN et al., 2002). Nesse método de propagação, pode-se manter algumas características genéticas interessantes da planta matriz (CHALFUN et al., 1994), mas gera indivíduos que variam morfológica e fisiologicamente entre si, além da vida útil produtiva da copa ser limitada pela longevidade do material utilizado como portaenxerto.

A estaquia pode ser realizada com estacas semilenhosas com folhas ou lenhosas sem folhas. Em ambos os casos, as mudas ficam prontas para o plantio no campo durante o inverno, mas, com a utilização de estacas semilenhosas, o tempo desde a estaquia até a obtenção da muda é menor (FINARDI, 1998).

A produção de mudas frutíferas por meio da estaquia é um método amplamente empregado, com algumas vantagens em relação à enxertia, tais como a facilidade de realização, baixo custo, rapidez na produção da muda e obtenção de descendentes com as mesmas características da planta matriz (AVERY e BEYL, 1991; KERSTEN et al., 1995; TONIETTO et al., 1997; DUTRA et al., 2002; HARTMANN et al., 2002). No entanto, o uso da estaquia para a propagação do pessegueiro no Brasil é limitado pela falta de tecnologia eficiente e segura de enraizamento das cultivares, justificando a necessidade de mais estudos.

A utilização exógena de reguladores vegetais, como o ácido indolbutírico (AIB) e a observância das melhores épocas para realização, têm facilitado a adoção da estaquia na propagação do pessegueiro (FACHINELLO et al., 1995).

Vários trabalhos têm sido realizados no sentido de tornar viável a propagação do pessegueiro com do uso de estacas. KAUNDAL et al. (1993) durante três anos de estudos, obtiveram $51,8 \%$, $45,2 \%, 43,2 \%$ e $38,6 \%$ de estacas lenhosas enraizadas das respectivas cultivares Florda Red, Sharbati, Shan-i-Punjab e Flordasun quando tratadas com $500 \mathrm{mg} \mathrm{dm}^{-3}$ de AIB. COUVILLON e EREZ (1980) obtiveram $100 \%$ de enraizamento tratando estacas semilenhosas de pessegueiro da seleção $1.372 \mathrm{com} 2500 \mathrm{mg} \mathrm{dm}^{-3}$ de AIB.

Com este trabalho objetivou-se avaliar o potencial de enraizamento de estacas semilenhosas de 15 cultivares de pessegueiro.

\section{MATERIAL E MÉTODOS}

O trabalho foi conduzido no período de março a junho de 2004, na EMBRAPA Transferência de Tecnologia, localizada no município de Canoinhas, SC, de coordenadas de $26^{\circ} 10^{\prime} \mathrm{S}$ e $50^{\circ} 23^{\prime} \mathrm{W}$, altitude de $765 \mathrm{~m}$ e clima Cfb.

$O$ delineamento experimental foi 0 inteiramente casualizado com seis repetições e 12 estacas por parcela. Foram utilizadas estacas semilenhosas de 15 cultivares de pessegueiro a saber: Capdeboscq, Charme, Chimarrita, Della Nona, Eldorado, Eragil, Granada, Jubileu, Leonense, Maciel, Marfim, Ouro, Pampeano, Precocinho e Riograndense. Ramos das brotações formadas na primavera de 2003 foram coletados de plantas com dois anos de idade, de pomares da Embrapa, em março de 2004. Os ramos foram levados para laboratório e as estacas foram preparadas com comprimento médio de $15 \mathrm{~cm}$ e diâmetro entre 4 e 6 $\mathrm{mm}$, com apenas um par de folhas cortadas ao meio na sua parte superior. A base das estacas foi raspada em ambos os lados, para melhor contato do regulador vegetal. As estacas foram pulverizadas com solução de captan $\left(2,5 \mathrm{mg} \mathrm{dm}^{-3}\right)$ antes de serem tratadas com o AIB e após a estaquia as pulverizações foram semanais.

Todas as estacas das diferentes cultivares foram tratadas com AIB na concentração de 1000 $\mathrm{mg} \mathrm{dm}^{-3}$, em imersão rápida por $5 \mathrm{~s}$ sua parte basal. A estaquia foi realizada em câmara de nebulização intermitente, com rega a cada $15 \mathrm{~min}$ por $20 \mathrm{~s}$ controlados por temporizador. As estacas foram colocadas para enraizar, em canteiros, com dimensões de $3 \mathrm{~m}^{2}$, contendo como substrato areia textura média, sendo enterradas até a metade.

Após 81 dias de cultivo foram analisadas as variáveis: porcentagem de estacas enraizadas, número de raízes por estaca e comprimento da maior raiz. Os dados em porcentagem foram transformados em arco-seno $(x / 100)^{0,5}$ e os dados quantitativos para $(x+1)^{0,5}$. Os resultados foram submetidos à análise de variância e as médias comparadas pelo teste de Scott-Knott a 5\% de probabilidade de erro.

\section{RESULTADOS E DISCUSSÃO}

As cultivares apresentaram potencial diferenciado de emissão de raízes adventícias, com diferença estatística na porcentagem de enraizamento. As cultivares Marfin, Eldorado, Maciel e Leonense foram as superiores apresentando percentuais de enraizamento de $90,27 \%, 79,16 \%$, $76,38 \%$ e $69,44 \%$, respectivamente (Tabela 1 ). Essa taxa elevada de enraizamento pode estar relacionada com o tipo de estaca utilizada, pois TOFANELLI et al. (2001) observaram a melhor capacidade de enraizamento de estacas semilenhosas em comparação com estacas lenhosas de pessegueiro com 6 a 7 anos de idade. As estacas semilenhosas apresentam tecido mais sensível à ação de 
reguladores vegetais e também são menos lignificadas do que as lenhosas, e assim, não apresentam anel de esclerênquima próximo do floema e córtex altamente lignificado, que poderiam constituir uma barreira à emergência das raízes (FACHINELLO et al., 1995). A estaquia realizada em abril ocasionou a obtenção de aproximadamente $30 \%$ de estacas enraizadas para a cultivar Eldorado, também tratada com $1000 \mathrm{mg} \mathrm{dm}^{-3}$ de AIB (RIBAS et al., 2007).

TABELA 1 - Porcentagem de estacas enraizadas, número médio de raízes e comprimento médio da maior raiz emitida por estaca semilenhosa de quinze cultivares de pessegueiro, tratadas com $1000 \mathrm{mg}$ $\mathrm{dm}^{-3}$ de ácido indol butírico. Canoinhas, SC. 2004.

\begin{tabular}{lccc}
\hline \multicolumn{1}{c}{ Cultivares } & Enraizamento (\%) & Número médio de raízes & $\begin{array}{c}\text { Comprimento médio da } \\
\text { maior raiz }(\mathrm{cm})\end{array}$ \\
\hline Marfim & $90,27 \mathrm{a}$ & $8,19 \mathrm{a}$ & $9,62 \mathrm{a}$ \\
Maciel & $76,38 \mathrm{a}$ & $5,63 \mathrm{~b}$ & $5,27 \mathrm{~b}$ \\
Eldorado & $79,16 \mathrm{a}$ & $3,28 \mathrm{c}$ & $7,89 \mathrm{a}$ \\
Leonense & $69,44 \mathrm{a}$ & $3,65 \mathrm{c}$ & $4,37 \mathrm{~b}$ \\
Charme & $61,11 \mathrm{~b}$ & $2,67 \mathrm{c}$ & $1,67 \mathrm{~d}$ \\
Della Nona & $59,72 \mathrm{~b}$ & $3,63 \mathrm{c}$ & $2,78 \mathrm{c}$ \\
Eragil & $58,33 \mathrm{~b}$ & $4,17 \mathrm{c}$ & $4,49 \mathrm{~b}$ \\
Capdeboscq & $52,77 \mathrm{~b}$ & $3,32 \mathrm{c}$ & $1,76 \mathrm{~d}$ \\
Precocinho & $50,00 \mathrm{~b}$ & $2,42 \mathrm{c}$ & $3,46 \mathrm{c}$ \\
Jubileu & $50,00 \mathrm{~b}$ & $2,94 \mathrm{c}$ & $2,97 \mathrm{c}$ \\
Chimarrita & $34,72 \mathrm{~b}$ & $1,90 \mathrm{~d}$ & $2,71 \mathrm{c}$ \\
Riograndense & $23,61 \mathrm{c}$ & $1,20 \mathrm{~d}$ & $0,85 \mathrm{e}$ \\
Pampeano & $22,22 \mathrm{c}$ & $1,58 \mathrm{~d}$ & $1,55 \mathrm{~d}$ \\
Ouro & $12,49 \mathrm{c}$ & $0,44 \mathrm{e}$ & $0,64 \mathrm{e}$ \\
Granada & $2,77 \mathrm{~d}$ & $0,02 \mathrm{e}$ & $0,05 \mathrm{e}$ \\
\hline C.V.(\%) & 18,5 & 18,5 & 14,6 \\
\hline
\end{tabular}

Médias seguidas da mesma letra na coluna não diferem entre si, pelo teste de Scott-Knott, a $5 \%$ de probabilidade.

As cultivares Charme, Capdbosque, Chimarrita, Della Nona, Eragil, Jubileu e Precocinho apresentaram enraizamento intermediário, entre 34,72 a $61,11 \%$, não diferindo entre si (Tabela 1 ). TREVISAN et al. (2000) também observaram enraizamento diferenciado na estaquia semilenhosa de nove cultivares de pessegueiro tratadas com $3000 \mathrm{mg} \mathrm{dm}^{-3}$ de AIB, obtendo maior percentual de enraizamento nas cultivares Premier $(58,4 \%)$, Chiripá $(50,8 \%)$, Pialo $(50 \%)$, Chimarrita (50\%), Planalto $(41,5 \%)$, Maciel $(38,8 \%)$ e Sinuelo $(29,7 \%)$, e as cultivares Flordaprince $(21,72 \%)$ e Peach $(7,24 \%)$ apresentaram os piores resultados. O comportamento diferenciado entre cultivares quanto à capacidade de formar raízes adventícias em estacas semilenhosas também foi observado com as cultivares Aurora, Biuti, Ouromel, Pérola de Mairinque, Tropical e Okinawa, e essas cultivares também responderam ao uso de AIB (TOFANELLI et al., 2001). Esses autores também afirmaram que o pessegueiro apresenta dificuldade de enraizamento de estacas, podendo considerar os porcentuais acima de $60 \%$ como razoáveis para a propagação do pessegueiro por estaquia, principalmente no caso das estacas lenhosas que dispensariam estruturas especiais para enraizamento. Essa diferença genética na habilidade de enraizamento já foi relatada entre cultivares de pessegueiro (TOFANELLI et al., 1997; RUFATO et al., 1999; OLIVEIRA et al., 2003; TOFANELLI et al., 2003) e nectarineira (MINDELLO NETO et al., 2005).

Para as cultivares Pampeano, Riograndense e Ouro a porcentagem de enraizamento foi baixa e para a cultivar Granada foi quase nula (Tabela 1 ). Isso pode representar uma deficiência na capacidade intrínseca de enraizamento desses genótipos. Entretanto, outros fatores como a época do ano em que se realizou a estaquia e a concentração de auxina utilizada, podem 
interferir na formação de raízes adventícias, pois com a cultivar Ouro já foram obtidas taxas acima de $90 \%$ de enraizamento na estaquia realizada em novembro (BIASI et al., 2000). A estaquia das cultivares Diamante, BR-2 e Capdeboscq apresentou melhores porcentagens de enraizamento nas épocas de primavera e verão, em comparação com o outono e o inverno. Nessas épocas, o enraizamento obtido para a cultivar Capdeboscq tratada com 2000 a $3000 \mathrm{mg} \mathrm{dm}^{-3}$ foi superior ao obtido no presente trabalho (DUTRA et al., 2002).

Observou-se neste trabalho que as cultivares que apresentaram maior enraizamento também apresentaram maior número de raízes, com destaque para a cultivar Marfim que apresentou maior número de raízes $(8,19)$ e maior comprimento da maior raiz $(9,62 \mathrm{~cm})$ (Tabela 1$)$. TOFANELLI et al. (2003) obtiveram resultados semelhantes para as cultivares Jóia e Okinawa, as quais apresentaram número de raízes de 11,3 e 8 e comprimento da maior raiz de 7 e $5 \mathrm{~cm}$, respectivamente. Esses autores sugeriram que o maior número de raízes pode resultar em comprimento de raiz maior nas estacas e que cada cultivar apresenta comportamento diferente quanto à formação de raízes. Talvez para as cultivares que apresentaram menor porcentagem de enraizamento, melhores resultados poderiam ter sido obtidos com concentrações mais elevadas de AIB, como já foi observado para algumas cultivares (TOFANELLI et al., 1997; RUFATO e KERSTEN, 2000; DUTRA et al., 2002; RIBAS et al., 2007).

\section{CONCLUSÕES}

As cultivares com maior potencial de enraizamento são Marfin, Eldorado, Maciel e Leonense.

Estacas semilenhosas das cultivares Granada, Ouro, Pampeano e Riograndense apresentam baixo potencial de emissão de raízes adventícias mesmo com o uso de $1000 \mathrm{mg} \mathrm{dm}^{-3} \mathrm{de}$ AIB.

\section{REFERÊNCIAS}

1. AVERY, J. D.; BEYL, C. B. Propagation of peach cuttings using foam cubes. HortScience, v. 26, n. 9, p. 1152-1154, 1991.

2. BIASI, L. A.; STOLTE, R. E.; SILVA, M. F. da. Estaquia de ramos semilenhosos de pessegueiro e nectarineira. Revista Brasileira de Fruticultura, v. 22, n. 3, p. 421-425, 2000

3. CHALFUN, N. N. J.; PASQUAL, M.; RAMOS, J. D.; LIMA, P. C.; CHALFUN JÚNIOR, A.; SILVA, T. das G. Efeito do anelamento e diferentes dosagens do ácido indolbutírico na propagação de estacas caulinares do pessegueiro "Okinawa". Revista Brasileira de Fruticultura, v. 16, n. 1, p. 119-126, 1994.

4. COUVILLON, G. A.; EREZ, A. Rooting survival and development of several peach cultivares propagated from semihardwood cuttings. HortScience, v. 15, n. 1, p. 41-43, 1980.

5. DUTRA, L.F.; KERSTEN, E.; FACHINELLO, J.C. Época de coleta, ácido indolbutírico e triptofano no enraizamento de estacas de pessegueiro. Scientia Agricola, v. 59, n. 2, p. 327-333, 2002.

6. FACHINELLO, J. C. et al. Propagação de plantas frutíferas de clima temperado. Pelotas: UFPEL, 1995. $179 \mathrm{p}$.

7. FACHINELLO, J. C.; KERSTEN, E.; MACHADO, A. A. Efeito do ácido indolbutírico no enraizamento de estacas lenhosas de pessegueiro cv. Diamante. Pesquisa Agropecuária Brasileira, v. 17, n. 2, p. 247-252, 1982.

8. FINARDI, N. L. Método de propagação e descrição de porta-enxertos. In: Medeiros, C. A. B.; Raseira, M. C. B. A cultura do pessegueiro. Brasília: EMBRAPA-SPI; Pelotas: EMBRAPA-CPACT, 1998. p. 100-129.

9. HARTMANN, H. T. et al. Plant propagation: principles and practices. 7. ed. New Jersey: Prentice Hall, 2002.880 p.

10. KAUNDAL, G. S. et al. Effect of growth regulators on the rhizogenesis of peach cultivars. Indian Journal of Horticulture, v. 50, n. 4, p. 318-326, 1993.

11. KERSTEN, E.; NACHTIGAL, J. C.; CALLOVY FILHO, C. Enraizamento de ameixeira (Prunus salicina, Lindl.) em diferentes épocas de coleta das estacas. Ciência Rural, v. 25, n. 1, p. 169-170, 1995.

12. MINDÊLLO NETO, U. R.; TELLES, C. A.; BIASI, L. A. Enraizamento de estacas semilenhosas de nectarineiras tratadas com diferentes concentrações de ácido indolbutírico. Revista Brasileira de Agrociência, v. 11, n. 3, p. 299-301, 2005.

13. OLIVEIRA, A. P. de; NIENOW, A. A.; CALVETE, E. O. Capacidade de enraizamento de estacas semilenhosas e lenhosas de cultivares de pessegueiro tratadas com AIB. Revista Brasileira de Fruticultura, v. 25, n. 2, p. 282-285, 2003.

14. RIBAS, C. P. et al. Ácido indolbutírico no enraizamento de estacas semilenhosas das cultivares de pessegueiro Della Nona e Eldorado. Scientia Agraria, v. 8, n. 4, p. 439-442, 2007.

15. RUFATO, L.; KERSTEN, E. Enraizamento de estacas de pessegueiro (Prunus persica (L.) Batsch), cvs. Esmeralda e BR2, submetidas à estratificação e ao ácido indolbutírico. Revista Brasileira de Fruticultura, v. 22, n. 2, p. 191-194, 2000.

16. RUFATO, L. et al. Efeito de diferentes concentrações de floroglucinol no enraizamento de estacas lenhosas de duas cultivares de pessegueiro (Prunus persica L. Batsch) tratadas com AlB. Revista Brasileira de Fruticultura, v. 21, n. 3, p. 297-300, 1999.

17. TOFANELLI, M. B. D. et al. Capacidade de enraizamento de estacas lenhosas e semilenhosas de cultivares de pessegueiro. Ciência e Agrotecnologia, v. 25, n. 4, p. 840-847, 2001.

18. TOFANELLI, M. B. D. et al. Enraizamento de estacas lenhosas e semilenhosas de cultivares-copa de pessegueiro em diferentes concentrações de ácido indolbutírico. Revista Brasileira de Fruticultura, v. 19, n. 2, p. 259-263, 1997.

19. TOFANELLI, M. B. D.; ONO, E. O.; RODRIGUES, J. D. Método de aplicação de ácido indolbutírico no enraizamento de estacas herbáceas de pessegueiro. Revista Brasileira de Fruticultura, v. 25, n. 2, p. 363-364, 2003.

20. TONIETTO, A.; DUTRA, L. F.; KERSTEN, E. Influência do ácido indolbutírico e ethephon no enraizamento de estacas de pessegueiro (Prunus persica (L.) Batsch). Ciência Rural, v. 27, n. 4, p. 567-569, 1997.

21. TREVISAN, R.; SCHWARTZ, E.; KERSTEN, E. Capacidade de enraizamento de estacas de ramos de pessegueiro (Prunus persica (L.) Batsch) de diferentes cultivares. Revista Científica Rural, v. 5, n. 1, p. 29-33, 2000. 
